\title{
Anatomía de la memoria: literatura y políticas del recuerdo
}

\author{
Anatomy of memory: \\ literature and the politics of remembrance
}

\author{
Wiosna Szukała \\ Uniwersytet im. Adama Mickiewicza w Poznaniu, Instytut Filologii Romańskiej \\ Zakład Literatury Hiszpańskiej i Iberoamerykańskiej \\ wiosna.szukala@amu.edu.pl
}

\begin{abstract}
This article set out to present the mutual relationship between two discourses that conceptualize the notion of memory: the theoretical-literary discourse and the politico-historical one. Literature, which is a constitutive element of the cultural memory system, plays two major roles in the society: it reflects the dominant tendencies in the collective memory, and secondly, it participates in the formation of individual, as well as collective, images of the past and the discourse that surrounds them. The study draws on, inter alia, the literary representations of memory in the works of Jorge Semprún (testimony) and Javier Cercas (postmemory). Both writers were keen on participating in the public debate on the policy of remembrance in Spain. This article focuses on the metaliterary and self-reflexive components of their writings and aims to position them in the wider theoretical context.
\end{abstract}

Keywords: memory, oblivion, remembrance, historical narrative, Semprún, Cercas

\section{INTRODUCCIÓN}

"Yo estoy enterrado en el Valle de los Caídos" es el título de un reportaje aparecido el 4 de diciembre de 2011 en el diario El País. Su protagonista, Eugenio de Azcárraga Vela, quien durante la Guerra Civil contendía en las filas del llamado bando nacional, en el alboroto de la batalla de Teruel fue confundido con otro soldado y dado por fallecido. Su nombre, junto a otros miles, quedó grabado en una de las paredes del Valle de los Caídos, un mausoleo que viene despertando una creciente 
controversia entre los españoles desde que Franco ordenó edificarlo, en honor y memoria de las víctimas de la guerra caídas en ambos bandos del conflicto. Muchos de los cuerpos sepultados fueron desenterrados de innumerables fosas comunes esparcidas por todo el territorio español para luego ser inhumados en el gigantesco santuario. El lugar central del mismo queda ocupado por la tumba del mismísimo Franco.

A la hora de realizar el reportaje, Azcárraga es un anciano de 95 años, aficionado a la vela. Tenía 20 años cuando estalló la guerra:

20 años y ninguna inquietud política. Por aquel entonces a mí me interesaba la natación - era campeón de 400 metros en mi ciudad-y las chicas. Vivíamos en Valencia y los republicanos mataron a un primo y una prima mía, de 20 y 19 años, por ser hijos de marqueses. Por ser ricos. Y yo decidí pasarme a la zona nacional. Si a mí me hubieran preguntado: “¿Usted qué prefiere: ser rojo, franquista o estar tranquilo?”, hubiese dicho que tranquilo, sin dudar. No me gustaba la boina roja, ni andar levantando el brazo para saludar. (Junquera, 2011, s. p.)

Iba a estudiar Derecho, pero en vez de ello se halló en la primera línea del frente, mas no era el riesgo de la muerte lo peor durante el combate:

para mí, el peor recuerdo de la guerra es en Teruel, en los sótanos del seminario donde se había refugiado la población civil. [...] En aquellos sótanos había cadáveres de mujeres destrozadas con abrigos rosas. Y niños deshidratados, porque allí no había ni comida, ni agua, ni nada. A los heridos les ponían vendas que les quitaban a los muertos. Yo estaba en la trinchera y solo bajé allí dos veces, pero de verdad que prefería estar en el sitio de más riesgo que ver aquello. (Junquera, 2011, s. p.)

Durante la guerra muchos de sus amigos y conocidos fallecieron, él mismo, herido, cayó en las manos de los republicanos, consiguió escapar amparándose en un bosque, donde apenas sí sobrevivió al hambre. Más tarde combatió en África. Su historia parece sacada de una novela, así de compleja y enmarañada, como miles parecidas contadas por los exsoldados de la guerra. "Todas las guerras están llenas de historias novelescas" —observa en Soldados de Salamina (2001), el narrador Javier Cercas. En respuesta del viejo y enfermo Miralles, el protagonista central de la novela, oye que "solo para quien no las vive. [...] Solo para quien las cuenta" (Cercas, 2011a: 196).

Azcárraga también rehúye rememorar aquellos tiempos. Aunque ha recorrido casi todo el mundo, dice que hay un lugar que con toda seguridad no va a visitar, es el Valle de los Caídos. A sus nietas prefiere hablarles sobre la navegación. Según él, no tiene sentido discutir sobre un pasado tan penoso como la Guerra Civil:

Yo lo dejaría como está. Las guerras civiles son todas absurdas y la nuestra también lo fue. Dependiendo de en qué sitio estuvieras, te tocaba de un bando o de otro y pasaban 
esas cosas absurdas como que dos hermanos estuvieran luchando entre ellos [...]. Nos matábamos unos a otros. Hay que olvidar. (Junquera, 2011, s. p.)

¿Hay que olvidar? La literatura española de los últimos años parece pregonar justamente lo contrario. El tema de la memoria, el menester de no olvidar el pasado, se ha convertido en uno de los más recurrentes de la narrativa reciente. La cantidad de publicaciones de género diverso consagradas a la reconstrucción de la historia se ha hecho tan extensa que ha llevado a los teóricos a hablar de "boom de la memoria". El fenómeno ha planteado toda una discusión teórica entre los estudiosos y los propios autores acerca de las formas adecuadas de recuperar el pasado. Las narraciones que reconstruyen los acontecimientos históricos, "desde el punto de vista de su comunicación social, pragmática, establecen una serie de categorías analíticas que los muestran diferentes de la literatura creativa en general" (López Navarro, 2007, p. 256). No obstante, cabe mencionar que no se trata de una discusión sobre las cuestiones meramente abstractas y formales, propias exclusivamente de las divagaciones teórico-literarias. Más bien al contrario. Estamos ante una literatura que "sabe estar muy próxima a los problemas que preocupan a la sociedad" (Potok, 2012, p. 9), que se implica en la realidad extratextual, social y política y que genera una reflexión sobre la dimensión tanto estética, como ética de la escritura. La relación entre la literatura y la memoria histórica es obviamente recíproca. De un lado, las obras literarias son capaces de expresar, reflejar los procesos mnemónicos dominantes en una sociedad dada; del otro, como medios de comunicación cultural, impactan también en el orden extratextual, influyendo en la construcción personal y social de las imágenes del pasado y la reflexión sobre acontecimientos históricos.

El objetivo del siguiente artículo es el análisis de la representación de la memoria histórica en la obra de dos escritores españoles: Jorge Semprún y Javier Cercas. Es importante mencionar que la manera de enfocar el tema de la memoria en ambos autores está lejos de ser coincidente. Son representantes de generaciones diferentes, cuentan con biografías diferentes, por lo que también sus narraciones pertenecen a géneros literarios distintos. Semprún, exrecluso del campo de concentración nazi en Buchenwald, narra sus experiencias personales, por lo que su escritura suele ser determinada como género testimonial. En cambio, Cercas, a diferencia del autor de El largo viaje, no fue testigo directo de los acontecimientos históricos que reconstruye en sus novelas. Su escritura representa la llamada "postmemoria", es decir, la recuperación del pasado que se basa en las narraciones de los demás. Ambos autores aluden a diferentes estrategias narrativas para relatar los hechos pasados. Lo que sí que les une, sin embargo, es un fuerte componente autorreflexivo de la escritura, reflejado en el nivel metaliterario de sus novelas. Asimismo, los dos no solo abordan la reflexión sobre los límites de la representación narrativa de la memoria histórica, sino que, además, suelen comprometerse en el debate público acerca de la política del Estado sobre la conservación del recuerdo. El debate, como cabe observar, 
entronca con una reflexión más amplia, internacional, así que nuestro artículo tratará de situar el pensamiento de los autores españoles en el contexto teórico general, europeo, lo que nos permitirá realizar una revisión multidimensional del concepto de la memoria.

\section{MEMORIA SILENCIO}

"Es totalmente imposible vivir sin olvidar" escribía Nietzsche (2000, p. 39). Jorge Semprún confesaba en una entrevista concedida con motivo de la publicación de su última novela que el olvido fue para él una gran terapia (2003a, s. p.). Este ilustre humanista, escritor español francófono, activista social y político, dedicó toda su vida a pregonar el menester de la memoria, la obligación de no olvidar. Justamente la memoria, el recuerdo, parecen ser tema primordial de sus novelas: ${ }^{1}$ "los libros de Semprún, desde los más declaradamente autobiográficos hasta los propiamente novelescos, caen dentro del género memorialístico: son libros de memorias, en los que el recuerdo regresa obstinadamente" - escribe Carlos Fernández, autor del trabajo Estrategias de la memoria en la obra de Jorge Semprún (2004, p. 70). El teórico divide la memoria en distintos tipos: memoria fáctica, memoria crítica y autocrítica, memoria ideológica, manipulada, memoria literaria... Semprún a través de los medios de expresión novelescos ejecuta un meticuloso análisis de todos estos tipos de memoria. Memoria que es fundamental e imprescindible pero, al mismo tiempo, hasta tal grado difícil y dolorosa que no puede realizarse sin concesiones, sin precauciones.

La memoria según Semprún, paradójicamente precisa del olvido: primero hay que olvidar, recurrir a la "memoria inhibida", "memoria silencio" (López Navarro, 2007, p. 257). A esta primera etapa de la inhibición forzosa de la memoria después del trauma, se refiere el dilema estancado en el título de uno de los más importantes libros del autor: La escritura o la vida (1994). De acuerdo con lo relatado por Semprún, justamente tal era la alternativa — ¿escribir o vivir? - ante la cual se hallaba muchas veces después de la liberación del campo y el fin de la guerra, cuan-

\footnotetext{
${ }^{1}$ Entre los libros de Semprún que abordan el tema de la memoria se suele mencionar sus narraciones dedicadas a la estancia en Buchenwald: El largo viaje (1963), Aquel domingo (1980), La escritura o la vida (1994), Viviré con su nombre, moriré con el mío (2001) y la única novela de Semprún escrita originalmente en español, consagrada al tema de la Guerra Civil y dictadura franquista: Veinte años y un día (2003). No obstante, Leuzinger, autora de la recién publicada monografía Jorge Semprún: Memoria cultural y escritura. Vida virtual y texto vital (2016), complementa esta lista, realizando un análisis de otros relatos del autor: La segunda muerte de Ramón Mercader (1969), La algarabía (1981), La montaña blanca (1986) y Netchaiev ha vuelto (1987), es decir, las novelas que, aunque "no suelen incluirse en el corpus clásico sobre la experiencia concentracionaria y política de Jorge Semprún” (p. 24), sí que emprenden la temática mnemónica.
} 
do volvió a ser un hombre libre. En el principio la descripción de las vivencias de Buchenwald se mostró irrealizable, pues el escritor se sometió a una "amnesia voluntaria”. Así comenta esta experiencia en su primera novela, El largo viaje (1963):

[...] la única manera de salvarse era guardar un largo periodo de silencio, Dios mío, años de silencio sobre aquel viaje. Quizá más adelante, cuando ya nadie hable de estos viajes, quizás entonces tendré algo que decir. Esta posibilidad flotaba de manera confusa en el horizonte de mi decisión. (2004, p. 107)

Y en una entrevista radiofónica:

[...] después de volver del campo de Buchenwald [...], cuando intenté escribir un relato que no fuera puro testimonio, puro documento, sino que fuera un poco más elaborado [...], yo no volvía a la vida, al contrario: permanecía en la memoria de muerte, totalmente. Porque claro, para recordar todo aquello, tenía que revivir todo aquello [...] y tuve la impresión y la certeza a veces, de que escribir me conducía al suicidio ni más ni menos, que esa experiencia terminaría con el suicidio si continuaba. Pues decidí, de ahí el título de otro libro, de un libro muy posterior La escritura o la vida y decidí optar por la vida. (Semprún, 2008, en línea)

El olvido, tachadura, entierro, destrucción de los recuerdos podría y, según confiesa el testigo, pudo traer sosiego, mas solo puede ser momentáneo, apenas bastante para sobrevivir. "Olvidar es un lujo", dice uno de los protagonistas de la novela Beltenebros de Antonio Muñoz Molina (1989, p. 56). Es imposible no hacerle caso a la memoria, ella persiste en el silencio, esperando.

Paul Ricœur en su libro La memoria, la historia, el olvido (2000) constata que la memoria es del pasado, la distancia temporal es pues un elemento esencial del fenómeno mnemónico (2006, p. 16). Semprún apunta sobre el distanciamiento temporal del que precisa no solo un testigo del crimen sino también un oyente de su relación; en caso contrario puede ocurrir lo contado por el escritor: "uno vuelve a casa, cuenta con pasión y con todo tipo de detalles en el círculo familiar la experiencia vivida, los sufrimientos padecidos. Pero nadie le cree. Estos relatos acaban creando una especie de malestar, provocando un silencio cada vez más espeso" (1995, p. 268). Como constata Zeitler Varela: "La dificultad está en tener que contar una historia increíble, inimaginable, invivible dirá el propio Semprún, pero no por ello indecible; el problema no es contarlo, sino tener un interlocutor que efectivamente esté dispuesto a escuchar" (2011, p. 4). Como si los oyentes, testigos indirectos, tampoco pudieran asumir un cargo tan grande como lo es la memoria del trauma, sin un período de inhibición de esta. Incluso las naciones enteras parecen padecer este periodo de memoria silencio, que funciona como un mecanismo de defensa, ante la impotencia para enfrentarse con el pasado traumático, que solo se hace posible con el paso de tiempo, en las generaciones posteriores. 
Con el distanciamiento viene la posibilidad del análisis, intento de comprensión, ajuste de cuentas. Carlos Fernández tal memoria la llama "crítica" (2004, p. 80). El ejemplo de funcionamiento de este tipo de memoria lo constituyen las reflexiones de Semprún sobre su propia actividad política. En su Autobiografía de Federico Sánchez (1977) el autor somete a juicio crítico la participación en el Partido Comunista Español, denominándose a sí mismo un "intelectual estalinizado" y denunciando el estilo panfletario de sus textos de antaño. El distanciamiento temporal, la evolución ideológica y la experiencia política adquirida permitieron al escritor percibir su propia biografía desde una perspectiva diferente.

Precisamos todos de la memoria crítica, ya que como sentenciaba célebremente el filósofo estadounidense George Santayana, "quienes no pueden recordar el pasado están condenados a repetirlo" $\left(2011\right.$, p. 172) ${ }^{2}$ Pero hay que preguntarse si basta con recordar y cómo hemos de hacerlo. "¿Y si lo estuviéramos haciendo mal y el problema residiera, no en el recurso a la memoria y al pasado, sino en el papel específico que quiere hacérseles jugar en las conclusiones que se saca de ello?" - reflexiona en su libro el filósofo y filólogo búlgaro-francés Tzvetan Todorov (2009, p. 9).

\section{UN OLVIDO FELIZ}

¿Es realmente la memoria un remedio contra el mal? —pregunta Todorov en su ensayo bajo el mismo título (2009). El autor observa que de hecho la memoria hoy se ha vuelto un término jurídico, político, introduciéndose en muchos países donde las lacras de las dictaduras y totalitarismos no han terminado de cicatrizar las llamadas "leyes de la memoria", que tienen por objeto indemnizar, recompensar a las víctimas sus sufrimientos, restablecer la justicia, castigar a los culpables. Todorov compara el funcionamiento de tales leyes en distintos países, haciendo hincapié en un caso insólito, peculiar en la escala mundial, como lo es Sudáfrica, que se enfrenta a una tentativa de ajustar las cuentas con los crímenes del apartheid.

Mientras que en Europa más de una vez la reivindicación de la justicia ha degenerado en un deseo de venganza, profundizando incluso la división entre las víctimas y los verdugos, centrándose sobre todo en la determinación de la pena, el Estado africano adoptó un modelo diferente de ajuste de cuentas histórico. Se convocó la Comisión de la Verdad y la Reconciliación, ante la cual fueron llamados los culpables de los crímenes y delitos que habían de confesar en público sus infracciones, a cambio de lo cual podían contar con la amnistía. Había solo una condición: tenían que confesar toda la verdad. De tal modo, según las palabras del propio Todorov:

\footnotetext{
${ }^{2}$ Trad. propia: "Those who cannot remember the past are condemned to repeat it".
} 
testimonios y confesiones juegan un papel catártico, las victimas reciben el reconocimiento público, los culpables sufren una humillación ante la nación [...]. De esta manera se consigue el establecimiento de la verdad — una verdad que no es confirmada ni científica ni legalmente, gracias a la acumulación de pruebas materiales, sino que reside en el acuerdo entre las dos partes. (2009, p. 28)

Lo que está en el centro de tal proceso de ajuste de cuentas no es tanto la culpa particular de uno u otro individuo, sino más bien la culpa en sí, el mecanismo que lleva al ser humano a cometer crímenes, sus causas, consecuencias, el intento de comprender. El objetivo que se plantea es la consecución de la verdad que ha de constituir el fundamento para la reconciliación. Con una reflexión acerca de la necesidad del perdón termina igualmente su libro La memoria, la historia y el olvido Paul Ricœur. Él también apela al ejemplo de Sudáfrica. Para el filósofo francés, una memoria justa significa un difícil perdón, es el olvido feliz, la memoria reconciliada. Al mismo tiempo queda preservada la frontera entre la amnistía y la amnesia.

\section{MEMORIA MANIPULADA}

Tendiendo a la reconciliación y la justicia tratamos de basarla en una memoria fiel, verdadera; pero podemos preguntarnos si tal realmente puede existir. Primo Levi observa que la memoria de la víctima y del verdugo nunca serán iguales, ninguna de ellas queda "inocente", libre de manipulación, deformación, tergiversación. ¿Puede cualquier memoria serlo? ¿Acaso la versión de los hechos no es siempre diferente según quien los reconstruye? (Levi, 2000, p. 10).

Mercedes Pombo, una de las protagonistas esenciales de Veinte años y un día (2003), la última novela de Semprún, lleva en el recuerdo los sucesos que habían conducido a la muerte de su marido; los ha reconstruido, contado y vuelto a relatar tantas veces que de hecho ya va repitiendo las palabras mecánicamente, sin saber. Al mismo tiempo - piensa- acaso podría contarse esa historia de una manera distinta, de mil maneras distintas:

Comoquiera que fuese, los acontecimientos de aquella tarde de julio parecían haberse vaciado de sustancia, como si sólo fuesen eso, un cuento, y al comenzar a contarlo una vez más, Mercedes se vio tediosamente sumida en la realidad de un relato y no en un relato de una realidad. Como si lo importante no fuese ya la verdad de la tarde del 18 de junio, veinte años antes, sino la del relato [...] Y ya se sabe que la verdad de un relato es engañosa [...]. (Semprún, 2003b, p. 55)

Así, de manera semejante, comenta el narrador de Soldados de Salamina la entrevista realizada a Sánchez Ferlosio, que le inspira a escribir su "relato real": "lo que Sánchez Mazas le había contado a su hijo (y lo que este me contó a mí) no era lo que recordaba que ocurrió, sino lo que recordaba haber contado otras veces" (2011a, p. 40). 
Paul Ricœur explica que la memoria siempre apela a una imagen ya ausente, reproduce ocurrencias del pasado en el presente, actúa como la pintura, que - según exponía Aristóteles - crea una imagen que es al mismo tiempo dos cosas: ella misma, es decir, una representación, y lo que representa, es decir, una versión de la cosa representada (2007, p. 5). La memoria es de alguna manera un reflejo del pasado, de la verdad y no el pasado mismo ni la verdad misma.

Tanto más apenas una versión, una mirada definida hacia el pasado es la memoria obligada, la emanada en un lema, a veces repetido sin reflexión profunda "tenemos que recordar". Según el filósofo francés, hablar sobre la "obligación" de la memoria es en cierta medida un abuso: impone un imperativo, lo que difícilmente puede cumplirse en el caso de las emociones humanas, ámbito dentro del cual se hallaría la memoria. Tal como no puede obligarse a nadie a que experimente determinadas emociones, tampoco puede exigirse la memoria. A menos que sea una memoria impuesta, política e ideológicamente manipulada. "No se pone en futuro una tarea de rememoración, o sea de retrospección, sin violentar el ejercicio mismo de la anamnesis —atrevámonos a decirlo- sin algo de manipulación" (Ricœur, 2007, p. 10). La memoria puede someterse a una manipulación bien consciente, puede ser tergiversada, falseada, desfigurada, silenciada, usada para fines particulares. Carlos Fernández acuña el término "teatro de la memoria":

a la manera de Pirandello, en el que caben las mentiras, las medias verdades, las amenazas veladas, las insidias. Un teatro de la memoria en el que los autores son al tiempo actores de una farsa, a veces siniestra, en la que el lector tiene dificultad para saber a ciencia cierta quién es quién, y que nos obliga a leer dichos documentos con mucha precaución pues están llenos de inexactitudes y de trampas. (2004, p. 83)

A su vez, Javier Cercas utiliza una expresión incluso más fuerte, denunciando el culto irreflexivo de la memoria, al que denomina "el circo de la memoria". El escritor critica esta tendencia de las sociedades contemporáneas de la industrialización y al mismo tiempo la trivialización de la memoria, la aproximación patética y exaltada al pasado: "la industria del entretenimiento genera kitsch, mentiras estéticas, un arte que no es arte sino sucedáneo de arte, la industria de la memoria genera una memoria embustera, sentimentaloide y falsamente heroica: puro cartón piedra, puro kitsch" (2014, s. p.) — constata el escritor. Según él, hemos convertido la memoria histórica en un negocio.

En contra de las apariencias, la memoria no solo es individual, estrechamente atada a la identidad del hombre y sus recuerdos personales. Es también una categoría social. Según Maurice Halbwachs, un sociólogo francés, creador del concepto de la memoria social, maestro y amigo de Semprún: "la memoria individual no es sino un retoño, un enclave, de la memoria colectiva" (cit. por Ricœur, 2007, p. 7). La memoria histórica, nacional, participa en el forjamiento de la mentalidad e identidad de 
sociedades enteras, que en conjunto reproducen, interpretan y conmemoran su pasado, su historia en el presente.

Ahora bien, la literatura es capaz de influir en esta formación de la cultura de la memoria de una sociedad dada. Como afirma Todorov, los artistas y los escritores son incluso "más responsables de cómo conocemos el pasado que los historiadores. Un novelista que cuenta bien un episodio puede tener mucha más influencia que un historiador que escribe de manera aburrida sobre el mismo acontecimiento" (2015, s. p.). Pero ¿cómo debemos narrar, escribir sobre lo pasado traumático sin caer en esa trampa de la nostalgia barata, del sentimentalismo cursi que reprocha a la época contemporánea Cercas? El problema de la representación de la memoria se hace especialmente tenso y problemático en el caso de las relaciones que abordan temas excepcionalmente importantes y dolorosos, que recurren a los acontecimientos históricos limítrofes, inimaginables, inconcebibles, increíbles. ¿Cómo hemos de contarlos?

\section{MEMORIA LITERARIA}

De cualquier manera que termine, esta guerra contra vosotros la hemos ganado; ninguno de vosotros quedará para contarlo, pero incluso si alguno lograra escapar, el mundo no lo creería [...]. Aunque alguna prueba llegase a subsistir y aunque alguno de vosotros llegara a sobrevivir, la gente dirá que los hechos que contáis son demasiado monstruosos para ser creídos: dirá que son exageraciones de la propaganda aliada y nos creerá a nosotros, que lo negaremos todo, no a vosotros. La historia del lager seremos nosotros quienes la escribamos. (Levi, 2000, p. 5)

Son palabras pronunciadas por uno de los soldados nazis que cita en su libro Los hundidos y los salvados (1986) Primo Levi. En estas palabras amenazadoras se hace visible otro problema: la memoria sobre los hechos que son "demasiado monstruosos para ser creídos".

Varios autores e intelectuales tomaron parte en el famoso debate lanzado por Theodor Adorno sobre si era posible la poesía después del lager y no pocos de ellos se declararon de manera unívoca en favor de la convicción de que el Holocausto queda como un fenómeno prácticamente irrepresentable, tanto a través del lenguaje, como por cualquier otro medio. Como si la única respuesta apropiada que merecerían aquellos acontecimientos fuera nuestro silencio.

La memoria transmitida a través de la literatura conlleva consecuencias graves: ¿cómo representar en una estructura novelesca una experiencia que queremos, por encima de todo, que no se olvide, si es una experiencia, un testimonio del mal que es a la vez inimaginable y perfectamente real? ¿Cómo superar en sí mismo, y tanto más en el lector, el instinto, el atavismo de esquivar, negar, bagatelizar, ningunear tal verdad? ¿Cómo hacerlo en particular en el caso de una novela, un 
género que se basa en la ficción, en la imaginación, lo que favorece aún más el instinto de incredulidad? Un lector bien puede pensar: "esta historia es demasiado compleja para ser real, la vida no lo es para tanto", "si esto no es más que una novela, y encima un poco cursi, patética", "la literatura siempre exagera, se base en las hipérboles...”. Ante estas posibles objeciones, numerosos historiadores han considerado que el único modo justo de representar aquellos acontecimientos, es una crónica de hechos puros; solo los datos desnudos aseguran el acercamiento a la autenticidad y veracidad de la representación de la enormidad de ese crimen.

Uno de los partidarios de dicha idea es Berel Lang, autor de Holocaust Representation: Art within the Limits of History and Ethics (2000). El filósofo llama a tales acontecimientos moralmente extremos, como un genocidio, acontecimientos de carácter "literal", paradigmáticos para toda la historia, sobre los cuales solo estamos autorizados a hablar de manera llana, directa y seca. Lang es un oponente resuelto del lenguaje metafórico utilizado para describir este tipo de acontecimientos históricos, considerando que este deforma la realidad pasada; incapaz de reflejar su naturaleza auténtica por lo que, en consecuencia, distrae la atención de los hechos sobre los cuales pretende dar pruebas (Lang, 2006, pp. 153-160). La mayor objeción de Lang la provocan los textos que tratan sobre los crímenes nazis aspirando al estatus de literatura, ya que la escritura literaria siempre pone en el escenario la poderosa figura del autor, que se interpone entre lo representado y la representación de tal forma que en función de él el modo de la figuración empleado podría variar. Por ello se hace evidente que existen muchas posibles versiones de la representación y esto lleva a Lang a la conclusión de que servirse de la literatura para la descripción de hechos como el Holocausto es inaceptable. Si cada narración se sirve de los recursos figurativos, ¿significa eso que no deben escribirse textos sobre acontecimientos históricos como la Shoah?

Lang considera que sí, que existe una forma apropiada de escribir sobre los sucesos llamados "literales", y para su denominación se sirve de un término acuñado por Roland Barthes: la escritura intransitiva (intransitive writing). En este tipo de escritura el autor no representa ninguna realidad exterior, independiente, sino que escribe, según las palabras del propio Lang, "a sí mismo", lo que anota es justamente su propia percepción y su propia consciencia (Lang, 2006, p. 16). La escritura misma constituye al autor. El resultado es parecido a los textos modernistas, ${ }^{3}$ como las obras de Proust, por ejemplo: lo que parece más significativo aquí es la descripción de la experiencia individual y esta ya no respeta tanto las fronteras entre lo objetivo y lo subjetivo, lo ficticio y lo real.

\footnotetext{
${ }^{3}$ Lang hace referencia al movimiento literario, surgido a finales del siglo XIX y principios del XX, influido por el experimentalismo y las distintas vanguardias artísticas. Sus principales representantes, en el ámbito literario, serían Joyce, Pound, Eliot, Wolf, entre otros. La escritura modernista ofrece técnicas — por ejemplo, fluir de la conciencia - contrapuestas a la narrativa clásica, que, según Lang, permiten la representación de experiencias traumáticas.
} 
El modelo de este tipo de narración lo constituye un fragmento del famoso libro de Primo Levi titulado El sistema periódico (1975). Levi termina su libro con una descripción sugestiva de un átomo de carbono que se encuentra en el vaso de leche que este se bebe y que luego el átomo viaja hacia su cerebro desde donde maneja su escritura:

Esta célula pertenece a un cerebro, y éste es mi cerebro, el de mi "yo" que escribe, y la célula en cuestión, y dentro de ella el átomo en cuestión, se encarga de mi labor de escribir, en un gigantesco y minúsculo juego que nadie ha descrito todavía. Es la célula que en este instante, surgiendo de un entramado laberíntico de sí es y no es, hace a mi mano, sí, correr sobre el papel en una determinada dirección y dejarlo marcado con estas volutas que son signos: un doble disparo, hacia arriba y hacia abajo, entre dos niveles de energía, está guiando esta mano mía para que imprima sobre el papel este punto: éste. (1999, p. 147)

Parece que la discusión teórica acerca de cómo deberíamos escribir sobre el Holocausto adquiere un matiz diferente confrontada con los textos de los mismos testigos de los crímenes relatados. ¿Quién podría sentirse autorizado para instruirlos sobre los métodos de contar su propia historia tan excepcional?

Lo característico para los testimonios de este tipo es la presencia de los enunciados metaliterarios que expresan la autoconciencia de autores, quienes bregan con las dificultades de relatar lo prácticamente imposible de transmitir. La obra de Semprún se inscribe en esta tendencia. El autor pone en cuestión la capacidad de los sobrevivientes de narrar de forma "eficaz" su experiencia. Su obra se la suele oponer a la de Levi: "La distancia temporal entre el fin de la Guerra y su momento detonante para el acto creativo le permite la reflexión respecto al uso de la ficción y el artificio literario que Levi no realizó previo a su escritura, y que para Semprún se encuentra en la selección de aquello que es narrable y que da forma a la representación del Holocausto" (Conejo, 2016, p. 66). El autor de La escritura o la vida es consciente de la imposibilidad de testimoniar, confiesa su incapacidad de captar la "verdad esencial" de lo vivido (1995, p. 103). El escritor en este sentido parece compartir la convicción de Agamben, conforme con quien cada testimonio contiene una "laguna", "vale en lo esencial por lo que falta en él" (2002, p. 33). Así que, la única forma de relatar la experiencia del Holocausto, conforme con el parecer de Semprún, es a través del lenguaje figurado. Para hablar sobre lo vivido, el autor necesita recurrir a la ficción:

[...] una duda me asalta sobre la posibilidad de contar [...] solo alcanzarán esta sustancia, esta densidad transparente aquellos que sepan convertir su testimonio en un objeto artístico, en un espacio de creación. [...] Únicamente el artificio de un relato dominado conseguirá transmitir parcialmente la verdad del testimonio. (1995, p. 25) 
A diferencia de Semprún, Cercas nos está convenciendo en numerosas entrevistas de que sus libros son "novelas sin ficción", de que están basadas tan solo en los "hechos reales". El autor de Anatomía de un instante alude en sus reflexiones metaliterarias sobre la representación de la memoria histórica a las ideas de Hayden White (2003), un destacado historiador estadounidense que postula tratar la historiografía como un género literario más. Siguiendo la teoría de White, el escritor opina que cada testimonio, relato, cualquier forma de la narración histórica siempre es una creación, manipulación, una de las versiones de la realidad, del pasado. Por lo tanto, según Cercas, el aplicar la ficción al relato del pasado resultaría redundante, equivaldría pues a ficcionalizar la ficción (2014, s. p.).

No obstante, al mismo tiempo, en el pensamiento de este autor está presente la convicción de que la historia y la literatura nos trasmiten la memoria sobre el pasado de distintas maneras:

¿[...] la novela puede contar la historia mejor que la historia? ¿[...] la novela puede sustituir a la historia? Mi respuesta es no. La historia y la literatura persiguen objetivos distintos; ambas buscan la verdad, pero sus verdades son opuestas: según sabemos desde Aristóteles, la verdad de la historia es una verdad factual, concreta, particular, una verdad que busca fijar lo ocurrido a determinadas personas en determinado momento y lugar; por el contrario, la verdad de la literatura [...] es una verdad moral, abstracta, universal, una verdad que busca fijar lo que les pasa a todos los hombres en cualquier momento y lugar. (Cercas, 2011b, s. p.)

La literatura se enfrenta a preguntas de naturaleza moral, ética, intenta comprender lo que se escapa a la imaginación humana y a las lenguas humanas, preguntas complejas e imprecisas a la vez, preguntas imposibles. Preguntas como las que se planteaba Jorge Semprún, emanadas de la creencia en que la literatura del pasado traumático es posible: "pero el envite no estribará en la descripción del horror. No solo en eso, ni siquiera principalmente. El envite será la exploración del alma humana en el horror del Mal" (Semprún, 1995, p. 143).

El vocablo 'recordar' viene del latín recordari, formado de re (de nuevo) y cordis (corazón). Por lo tanto, etimológicamente, recordar significa volver a pasar por el corazón. Según Aristóteles, la memoria es una experiencia, lo que queda de la sensación. En un acto organizado con motivo de la publicación de Veinte años y un día, Emilio Lledó, reconocido filósofo español, amigo de Semprún, decía que solo los seres humanos son capaces de repetir las sensaciones:

[...] de tener sensaciones y de que no se les pierdan en el latido de los días, en el latido de la existencia, en el latido de la angustia de vivir, de la necesidad de vivir; sólo los seres humanos son capaces de asimilar las sensaciones en la psyche, en el ánimo, en la mente, en el logos, y de hacer la palabra, más allá o más acá del latido, del instante, de la punzada del presente. (Antich, Lledó, Ridao \& Semprún, 2003, p. 41) 
Parece que aquella sensación, su recuerdo, mejor deja eternizarse en la literatura; acaso en el arte en general.

\section{A MODO DE CONCLUSIONES}

Tanto Semprún, como Cercas se mostraron contrarios a la promulgación de la Ley de la Memoria Histórica (2007). Este segundo, en un artículo en El País, escribía:

a mí no me hace ninguna gracia que el Estado se ponga a legislar sobre la historia, no digamos sobre la memoria - como no me haría ninguna gracia que se pusiera a legislar sobre la literatura-, porque la historia deben hacerla los historiadores, no los políticos, y la memoria la hace cada uno, y porque una ley de este tipo recuerda embarazosamente los métodos de los estados totalitarios, que saben muy bien que la mejor manera de dominar el presente es dominar el pasado [...]. (2008, s. p.)

Aunque podría parecer que sobre la historia y la memoria de la Guerra Civil ya se ha escrito todo lo posible, el tema sigue siendo vivo y polémico, sin dejar despertar las emociones entre los ciudadanos contemporáneos. Cada semana se publican en los periódicos más importantes de España artículos consagrados a los recuerdos de la Guerra Civil. Cada año se organizan protestas de los familiares de los fallecidos, que reclaman la exhumación de sus familiares enterrados en las fosas comunes.

Hace un año, en el 40 aniversario de la muerte de Franco, en toda España se convocaron manifestaciones en contra de la permanencia de los restos del dictador al lado de sus víctimas. Los manifestantes se concentraron bajo el lema "40 años son demasiado. ¡Fuera la tumba del dictador!” y pidieron la reconversión del recinto en un memorial antifascista. Afortunadamente, se consiguió evitar incidentes graves. Como informó al día siguiente la agencia EFE, "España vivió el aniversario con serenidad ya que una buena parte de la población española no había nacido en 1975 y la figura de Franco ha ido cayendo en el olvido" (2015, s. p.).

Eugenio Azcárraga no quiere participar en la discusión sobre el mausoleo del Valle de los Caídos, comprende que a algunas familias les resulte difícil aceptar el hecho de que sus familiares cercanos yazcan junto a su verdugo, Franco, pero para él esto ya no tiene importancia. Considera "estúpida" la Ley de Memoria Histórica y como admite en el reportaje mencionado al principio, nunca va al cementerio para dejar flores en la tumba de su madre, cree que eso "no sirve de nada". Después agrega: "Sirve que me acuerde de ella. Eso sí" (cit. por Junquera, 2011, s. p.). 


\section{BIBLIOGRAFÍA}

Agamben, G. (2005 [1999]). Lo que queda de Auschwitz. El archivo y el testigo. Homo Sacer III (trad. A. Cuspinera). Valencia: Pre-textos.

Antich, X., Lledó, E., Ridao, J. M. \& Semprún, J. (2003). "La necesidad de la memoria. Coloquio en torno a Veinte años y un día". Letras libres, 27, 41-45.

Cercas, J. (2011 [2001]). Soldados de Salamina, Barcelona: Tusquets.

— (2008, 1 febrero). "La tiranía de la memoria". El Pais, Babelia. Recogido en: http://elpais.com

— (2011, 25 junio). "La tercera verdad", El País. Recogido en: http://elpais.com

- (2014, 15 noviembre). "Javier Cercas: La memoria histórica se ha vuelto una industria" (entrevista por G. Altares). El País Semanal. Recogido en: http://cultura.elpais.com

EFE (2015). "España vive con serenidad los 40 años de la muerte de Franco". Recogido en: http://www.efe.com

El País (2011, 27 julio). "Semprún y la señorita Maura". Recogido en: http://elpais.com

Conejo, Yazmín (2016). "Los límites de la representación y la reflexión en torno al problema de la ficcionalización y estetización en la literatura de posguerra, el caso de los sobrevivientes". Memoria y Sociedad, 20 (40), 58-69.

Fernández, C. (2004). "Estrategias de la memoria en la obra de Jorge Semprún". Historia, Antropología y Fuentes Orales, 32, 69-87.

Junquera, N. (2011, 4 diciembre). "Yo estoy enterrado en el Valle de los Caídos". El País. Recogido en: http://elpais.com

Lang, B. (2006). Nazistowskie ludobójstwo (trad. A. Ziębińska-Witek). Lublin: Wydawnictwo Uniwersytetu Marii Curie-Skłodowskiej.

Leuzinger, M. (2016). Jorge Semprún: Memoria cultural y escritura. Vida virtual y texto vital. Madrid: Verbum.

Levi, P. (1999). El sistema periódico (trad. C. Martín Gaite). Madrid: Alianza.

- (2000 [1986]). Los hundidos y los salvados (trad. P. Gómez Bedate). Barcelona: Muchnik.

Lluch, J. (2004). "Reflexiones aubianas en torno a la escritura de El laberinto mágico". En D. A. Cusato, L. Frattale, G. Morelli, P. Taravacci \& B. Tejerina (Eds.), Letteratura della memoria, Atti del XXI Convegno (Associazione Ispanisti Italiani), Salamanca, 12-14 septiembre 2002 (vol. 1., pp. 175-186), Messina: Andrea Lippolis Editore.

López Navarro, M. J. (2007). “Jorge Semprún: el ciclo de «novelas de la anamnesis»". Itinerarios: Revista de estudios lingüisticos, literarios, históricos y antropológicos, 6, 255-262.

Muñoz Molina, A. (1989). Beltenebros. Barcelona: Seix Barral.

Nietzsche, F. (2000 ([1874]). De la utilidad y los inconvenientes de la historia para la vida (trad. D. Garzón). Madrid: Edaf.

Potok, M. (2012). Estrategias literarias para la recuperación de la memoria histórica. La narrativa actual frente a la guerra civil. Études Romanes de Brno, 33 (2), 9-20.

Ricœur, P. (2007). "Historia y memoria. La escritura de la historia y la representación del pasado". En A. Pérotin-Dumon (Ed.), Historizar el pasado vivo en América Latina. Recogido en: http://www.historizarelpasadovivo.cl/downloads/ricoeur.pdf (30 septiembre 2016).

- (2006 [2000]). Pamięć, historia, zapomnienie. Kraków: Universitas.

Santayana, G. (2011 [1905]). The life of reason. Cambridge: The MIT Press.

Semprún, J. (2004 [1963]). El largo viaje (trad. J. \& R. Conte). Barcelona: Tusquets.

- (1995 [1994]). La escritura o la vida (trad. T. Kauf). Barcelona: Tusquets.

- (2003a). "La memoria como escritura: Entrevista con Jorge Semprún" (entrevista por R. Cayuela Gally). Letras Libres. Recogido en: http://www.letraslibres.com 
- (2003b). Veinte años y un día. Barcelona: Tusquets.

- (2008). "Jorge Semprún y los campos de concentración nazis" [Programa de radio]. Informa RN, Departamento español de Radio Nederland. Recogido en: https://www.youtube.com/watch?v=7_ QmLezLoy8\&list=PL5838E8EDF391B2D0\&index=4 (30 septiembre 2016).

Todorov, T. (2009). La memoria, ¿un remedio contra el mal? Barcelona: Arcadia.

- (2015, 11 junio). "La memoria tiene una potencia que la historia nunca alcanza" (entrevista por D. Gascón). Letras Libres. Recogido en: http://www.letraslibres.com

White, H. (2003). El texto histórico como artefacto literario. Barcelona: Paidós Ibérica.

Zeitler Varela, M. (2011). "Historia, memoria y testimonio: una lectura de Primo Levi y Jorge Semprún desde Hayden White". En IV Seminario Internacional Políticas de la Memoria: Ampliación del campo de los Derechos Humanos. Memoria y Perspectivas. Buenos Aires, 28 septiembre - 1 octubre 2011. Recogido en: http://conti.derhuman.jus.gov.ar/2011/10/seminario.shtml (30 septiembre 2016). 